\title{
FINAL TECHNICAL REPORT FOR DOE AWARD DE-FG02-98ER62581.
}

Award expired on March 14, 2005

\section{Title: Study of Heterogeneouse Processes Related to the Chemistry of Tropospheric Oxidants and Aerosols \\ PI: \\ Paul Davidovits \\ Co-PI's \\ D.R. Worsnop, J.T. Jayne and C.E. Kolb}

Objective: The objective of the studies was to elucidate the heterogeneous chemistry of tropospheric aerosols. Experiments were designed to measure both specifically needed parameters, and to obtain systematic data required to build a fundamental understanding of the nature of gas-surface physical and chemical interactions.

Approach: Three novel techniques developed by Boston College/Aerodyne group were used to study heterogeneous interactions: a droplet train apparatus, a bubble train apparatus and the most recently constructed flow reactor/aerosol mass spectrometer kinetics apparatus.

\section{PROGRESS REPORT}

The following projects were completed during the DOE award period:

1. Mass and Thermal Accommodation Coefficients of $\mathrm{H}_{2} \mathrm{O}(\mathrm{g})$ on Liquid Water as a Function of Temperature. In the Progress Report of December 2000, the completion of mass and thermal accommodation coefficient measurements of $\mathrm{H}_{2} \mathrm{O}(\mathrm{g})$ on liquid water was reported. These are parameters of central importance both from a practical and theoretical point of view. Because of the centrality of these parameters particularly of the mass accommodation coefficient, there have been 40 laboratory experiments over the past 75 years, designed to measure the mass accommodation coefficient. Past experimental techniques did not lead to a reliable determination of the mass accommodation coefficient. Values in the literature range from 0.001 to 1 . The uptake studies of $\mathrm{H}_{2} \mathrm{O}(\mathrm{g})$ on liquid water reported by the $\mathrm{BC} /$ Aerodyne group were performed with a droplet train flow-tube apparatus under conditions that circumvent difficulties that impeded accurate determination of these parameters in previous experiments. The manuscript describing this work has been accepted for publication as a Feature Article in the Journal of Physical Chemistry. See Publication 1 and also Publications 4, and 11

2. Uptake of Gas Species on Organic Liquids (a) Uptake of $\mathrm{HCl}(\mathrm{g})$ and $\mathrm{HBr}(\mathrm{g})$ on Ethylene Glycol Surfaces as a Function of Relative Humidity and Temperature. Organic compounds are a significant component of tropospheric aerosols. In the present experiments, ethylene glycol was selected as a surrogate hydrophilic organic compound for a study of surface properties of organic liquid-aqueous solutions. The mass accommodation coefficient of gas phase $\mathrm{HCl}$ and $\mathrm{HBr}$ on ethylene glycol-water surfaces has been measured as a function of water mole fraction (0 to 1) and temperature. The gas uptake studies were performed under liquid-vapor equilibrium conditions using a droplet train flow reactor. The mass accommodation coefficient for $\mathrm{HCl}$ on pure ethylene glycol increases from about $0.40+/-0.06$ at $303 \mathrm{~K}$ to $0.79+/-0.12$ at $258 \mathrm{~K}$. Such negative temperature dependence has been observed in studies of gas uptake by aqueous surfaces. The $\mathrm{HBr}$ mass accommodation coefficient on ethylene glycol is near unity independent 
of temperature in the range studied. The mass accommodation coefficient (a) on the ethylene glycol-water solution is well represented by:

$\mathrm{a}=\mathrm{a}_{\mathrm{H} 2 \mathrm{O}} \mathrm{X}(\mathrm{s})_{\mathrm{H} 2 \mathrm{O}}+\mathrm{a}_{\mathrm{EG}}\left(1-\mathrm{X}(\mathrm{s})_{\mathrm{H} 2 \mathrm{O}}\right)$

where $\mathrm{X}(\mathrm{s})_{\mathrm{H} 2 \mathrm{O}}$ is the water fractional surface coverage obtained via the surface tension of the solution and the subscripted a's are the mass accommodation coefficients on pure water and ethylene glycol. The $\mathrm{D}-\mathrm{H}$ isotope exchange probability of $\mathrm{DCl}$ on the gas-liquid interface of ethylene glycol was also studied and was measured to be 1, implying that the thermal accommodation coefficient is also 1 . See Publication 2.

3. Uptake of Gas Species on Organic Liquids; Uptake by Octanol. Octanol was selected as a model for a more hydrophobic organic compound. In the absence of water vapor, (R.H. = 0) the mas accommodation coefficient for $\mathrm{HCl}$ on dry octanol is small, close to zero. On the other hand, the uptake coefficient of $\mathrm{HBr}$ on octanol at R.H. $=0$ is close to unity. The difference between $\mathrm{HCl}$ and $\mathrm{HBr}$ chemistry may explain the observed uptake in the dry environment. The unexpected aspect of the data is the behavior of the uptake as a function of relative humidity. As the concentration of water vapor increases, the observed uptake coefficient of $\mathrm{HCl}$ increases and that of $\mathrm{HBr}$ decreases. At about 50\% R.H., the uptake coefficients of both molecules reach a value which is the same (within experimental accuracy) as the uptake on pure water.

On the face of it, the data suggest that for the process of surface interaction, at humidity greater than $50 \%$, octanol behaves as if the surface were pure water. Not only the magnitude but also the temperature dependence of the mass accommodation coefficient on octanol in this region is the same as that of pure water And yet it is not likely that this water-like kinetic behavior is due to an actual layer of water covering the surface. Certainly, one would not expect a coating of water to form on a hydrophobic liquid such as octanol at these low relative humidities. In fact we have measured the uptake of a-pinene on octanol. The mass accommodation coefficient is independent of R.H. and is larger than 0.1 , not at all characteristic of the small a-pinene uptake expected on water.

Additional experiments were performed studying the uptake on octanol of $\mathrm{HI}(\mathrm{g})$ and acetic acid. D-H isotope exchange studies were also performed with $\mathrm{D}_{2} \mathrm{O}$ and deuterated acetic acid. The results support the picture of the process presented in last year's report. Namely, on colliding with the organic liquid surface, the $\mathrm{HX}(\mathrm{HCl}, \mathrm{HBr}$, or $\mathrm{HI})$ molecule forms a surface species that resides on the surface with some characteristic lifetime. If during its lifetime the surface HX species encounters a sufficient number of water molecules impinging on the surface, it may form a small complex with the water molecules, perhaps inducing ionization and entry as ions into the bulk liquid. This picture is consistent with our earlier nucleation model of mass accommodation on aqueous surfaces. Such clustering and ionization in the presence of water molecules would result in the surface exhibiting water-like behavior rather than one characteristic of the liquid itself. Ionization within the hypothetical surface water complex is not a necessary aspect of this model. Other interactions of hydrophylic gas phase species may likewise induce water-like kinetic interactions at the interface. See Publication 8.

4. Rate Constant for the Reaction of $\mathbf{C l}_{2}(\mathbf{a q})$ with $\mathbf{O H}^{-}$. Elevated levels of molecular chlorine in the nighttime marine boundary layer were recently measured in coastal air of Long Island, confirming earlier deductions about atmospheric reactive chlorine concentrations, derived both 
from the deficit of $\mathrm{Cl}^{-}$in sea salt aerosols and field data on hydrocarbon oxidation rates. These important observations motivated several studies examining possible mechanisms for the release of photo labile chlorine species from sea-salt aerosol particles. A number of heterogeneous mechanisms have been proposed to explain the conversion of sea-salt chloride to aqueous molecular chlorine. Chlorine hydrolysis is one possible pathway for the conversion of aqueous chlorine to an aerosol reservoir species. The modeling of this process requires the knowledge of the second order rate constant for the reaction $\mathrm{Cl}_{2(\mathrm{aq})}+\mathrm{OH}^{-}--->\mathrm{HOCl}+\mathrm{Cl}^{-}$. Literature values for this rate constant span four orders of magnitude. The second order rate $(\mathrm{k})$ constant for this reaction was determined by measuring the uptake of gas phase chlorine into water in a bubble train flow reactor. These measurements avoided some of the difficulties encountered in earlier studies. Data were obtained at three temperatures: $275 \mathrm{~K}, 293 \mathrm{~K}$, and $303 \mathrm{~K}$ yielding: $\mathrm{k}=(1.3$ +/- 0.5) E8, $(6+/-2)$ E8 and $(8+/-3)$ E8 respectively. The atmospheric relevance of the chlorine hydrolysis reaction is examined. See Publication 5.

5. Kinetics of Submicron Oleic Acid Aerosols with Ozone; a Novel Aerosol Mass Spectrometric Technique. Reaction kinetics of submicron oleic acid aerosols with ozone were studied using the recently developed aerosol mass spectrometric technique. In the apparatus a flow of size-selected aerosols is introduced into an atmospheric-pressure flow reactor where the particles are exposed to a known density of reactive trace gas for a controlled period of time (1 to $7 \mathrm{sec}$.). The aerosol flow is directed into an aerosol mass spectrometer (AMS), for efficient particle size and composition analysis. The oleic acid-ozone studies yielded data which were used to (a) model quantitatively the kinetics process, (b) determine the aerosol size change due to uptake of the trace gas, (c) assess reaction stoichiometry, and (d) obtain qualitative information about the volatility of the reaction products. The reactive collision probability for ozone on oleic acid particles, obtained from modeling is $1.6(+/-0.2) \times$ E-3 with an upper limit for the reactodiffusive length of $\sim 10 \mathrm{~nm}$. The data yielded a value for the product $\mathrm{H}(\mathrm{Dk}) 1 / 2=0.33+/-0.03$ $\mathrm{M} 1 / 2 \mathrm{~atm} \mathrm{~cm} \mathrm{~s}^{-1}$, where $H, D$, and $k_{2}$ are the Henry's Law coefficient, diffusion coefficient, and reaction coefficient respectively, for ozone in oleic acid. For pure oleic acid aerosols in polluted atmospheres, half-life with respect to $\mathrm{O}_{3}$ reactions is estimated to be about 2 minutes. The studies and the atmospheric implications of the result are discussed in Publication 3, 10 and 16.

6. Uptake of Gas Phase Species on 1-Octanol: 1. Uptake of $\alpha$-Pinene, $\gamma$-Terpinene, $p$ -
Cymene and 2-Methyl-2-hexanol as a Function of Relative Humidity and Temperature. Using a droplet train apparatus, the uptake by 1-octanol of gas phase $\alpha$-pinene, $\gamma$-terpinene, $p$ cymene and 2-methyl-2-hexanol was measured as a function of relative humidity and temperature $(263 \mathrm{~K}$ to $293 \mathrm{~K})$. 1-octanol was selected as a surrogate for hydrophobic oxygenated organic compounds found in tropospheric aerosols. The mass accommodation coefficients $(\alpha)$ of $\gamma$-terpinene, $p$-cymene and 2-methyl-2-hexanol obtained from these measurements exhibit negative temperature dependences. The upper and lower values of $\alpha$ at $265 \mathrm{~K}$ and $290 \mathrm{~K}$ respectively are: for $\gamma$-terpinene 0.12 and 0.076 ; for $p$-cymene 0.20 and 0.097 ; for 2-methyl-2-hexanol 0.25 and 0.11 . The uptake of $\alpha$-pinene is solubility limited, yielding values for the product $\mathrm{HD}_{1}{ }^{1 / 2}$ for $\alpha$-pinene in 1-octanol $\left(\mathrm{H}=\right.$ Henry's law constant, $\mathrm{D}_{1}=$ liquid phase diffusion coefficient). Using estimated values of $D_{1}$ the Henry's law constant is obtained as $\ln H$ $(\mathrm{M} / \mathrm{atm})=-(6.59 \pm 1.16)+(3.80 \pm 0.31) \times 10^{3} / \mathrm{T}$. The presence of water vapor does not affect the uptake of the above organic gas phase species. Uptake of the gas phase species benzene, $\mathrm{H}_{2} \mathrm{O}, \mathrm{SO}_{2}$, and $\mathrm{H}_{2} \mathrm{~S}$ was also studied and was found to below the detection limit of the droplet 
apparatus. This implies that the uptake coefficient for these species is less than $10^{-3}$ for trace gas/liquid droplet interaction times of $2 \times 10^{-3}$ to $1.5 \times 10^{-2}$ seconds. See Publication 7 .

7. Uptake of Gas Phase Species on 1-Octanol; Uptake of Hydrogen Halides and Acetic Acid as a Function of Relative Humidity and Temperature. Using a droplet train apparatus, the uptake of gas phase $\mathrm{HCl}, \mathrm{HBr}, \mathrm{HI}$ and acetic acid was measured on 1-octanol to probe the nature of the hydrophobic organic surface as a function of relative humidity (R.H.) and temperature. These measurements yielded the mass accommodation coefficient $(\alpha)$. In the absence of water vapor, $\alpha$ for both $\mathrm{HBr}(\mathrm{g})$ and $\mathrm{HI}(\mathrm{g})$ is unity independent of temperature $(265 \mathrm{~K}$ to $290 \mathrm{~K}$ ). The mass accommodation coefficients for acetic acid and $\mathrm{HCl}$ are smaller, about 0.3 for acetic acid and 0.01 for $\mathrm{HCl}$ at $273 \mathrm{~K}$, displaying negative temperature dependence. The value of a for acetic acid is essentially independent of relative humidity. However, values of $\alpha$ for $\mathrm{HBr}, \mathrm{HI}$ and $\mathrm{HCl}$ change dramatically as a function of R.H. As the relative humidity increases, the $\alpha$-values for $\mathrm{HBr} \mathrm{HI}$ decrease, and $\alpha$ for $\mathrm{HCl}$ increases. At a relative humidity of about $50 \%, \alpha$ for all three species approaches values close to that on pure water.

Even at a low relative humidity of $50 \%$, seemingly the uptake of every $\mathrm{HX}$ molecule that strikes the octanol surface is governed by water. At first glance it seems as if, at these low humidities, the entire octanol surface is covered by water molecules. Yet we know that this cannot be the case. Only a very small fraction of a relatively hydrophobic surface, such as octanol, is expected to be occupied by water. This is confirmed by the measured uptake of organic gases and acetic acid which is unaffected by humidity. How then is one to account for the large effect of water vapor on an essentially hydrophobic octanol surface?

We begin by assuming that in the presence of gas phase water, the octanol surface is in dynamic equilibrium with the water vapor. In other words, in equilibrium with water vapor there is a population of water molecules bound to the octanol surface. An HX molecule that lands on the octanol surface (and thermally accommodates to it) now may take three pathways. As before, it may 1). desorb from the surface 2). enter into the bulk liquid, or in the presence of surface-bound water molecules, (3) it may encounter a surface water molecule and form a new $\mathrm{HX}-\mathrm{H}_{2} \mathrm{O}$ surface complex at a density. The rate of formation for this complex is $\mathrm{n}_{\mathrm{w}} \mathrm{k}_{\mathrm{D}}$, where $\mathrm{k}_{\mathrm{D}}$ is the surface diffusion controlled rate constant for the formation of the $\mathrm{HX}$ and $\mathrm{H}_{2} \mathrm{O}$ surface species and $\mathrm{n}_{\mathrm{w}}$ is the density of the surface bound water. The $\mathrm{HX}-\mathrm{H}_{2} \mathrm{O}$ surface complex is governed by its own desorption and solvation rates. If the rate $\mathrm{n}_{\mathrm{w}} \mathrm{k}_{\mathrm{D}}$, is sufficiently large, all the $\mathrm{HX}$ molecules that land on the octanol surface are converted into a $\mathrm{HX}-\mathrm{H}_{2} \mathrm{O}$ complex and the uptake is governed entirely by the surface kinetics of the complex. This model provides a quantitative explanation of the observed results. See Publication 8.

\section{Uptake of Organic Gas Phase Species on 1-Octanol, 1-Methylnaphthalen and Valeric}

Acid. Using a droplet train apparatus, mass accommodation coefficient measurements were completed on three organic liquids; 1-octanol, 1-methylnaphthalen and valeric acid. These organic liquids were selected as surrogates for liquids commonly found in tropospheric aerosols. Specifically, octanol was selected as a surrogate for oxygenated organic compounds, 1methylnapthalene as a surrogate for hydrophobic and aromatic hydrocarbons, and valeric acid was selected as a surrogate for organic acids.

Among the gas phase species studied were m-xylene, ethylbenzene, butylbenzene, apinene, g-terpinene, and 2-methyl-2-hexanol p-cymene and benzene. Mass accommodation 
coefficients were measured as a function of temperature (265 K to $296 \mathrm{~K})$. The study of these three liquids completes a set of experiments that revealed some general principles governing the uptake of organic gases by organic liquids.

Uptake on 1-octanol: The mass accommodation coefficients of g-terpinene, $p$-cymene and 2methyl-2-hexanol were obtained. These coefficients all exhibit negative temperature dependences. The upper and lower values of the mass accommodation coefficients at $265 \mathrm{~K}$ and 290 $\mathrm{K}$ respectively are: for g-terpinene 0.12 and 0.076 ; for $p$-cymene 0.20 and 0.097 ; for 2 methyl-2-hexanol 0.25 and 0.11 . The uptake of a-pinene is solubility limited, yielding values for the product $\mathrm{HD}_{1}{ }^{1 / 2}$ for a-pinene in 1-octanol $\left(\mathrm{H}=\right.$ Henry's law constant, $\mathrm{D}_{1}=$ liquid phase diffusion coefficient). Using estimated values of $\mathrm{D}_{1}$ the Henry's law constant is obtained as $\ln \mathrm{H}$ $(\mathrm{M} / \mathrm{atm})=-(6.59+/-1.16)+(3.80+/-0.31) \times 10(3) / \mathrm{T}$. The presence of water vapor does not affect the uptake of the above organic gas phase species. Uptake of benzene was also studied and was found to below the detection limit of the droplet apparatus. This implies that the uptake coefficient for this species is less than $10^{-3}$ for trace gas/liquid droplet interaction times in these studies (2 $\mathrm{ms}$ to $15 \mathrm{~ms}$ ).

Uptake on 1-methylnapthalene: The mass accommodation coefficients of gas phase m-xylene, ethylbenzene, butylbenzene, a-pinene, g-terpinene, p-cymene and 2-methyl-2-hexanol were measured as a function of temperature ( $265 \mathrm{~K}$ to $296 \mathrm{~K})$. The mass accommodation coefficients of all the molecules obtained from these measurements exhibit a negative temperature dependence. The upper and lower values of the mass accommodation coefficient at $265 \mathrm{~K}$ and $296 \mathrm{~K}$ respectively are: for $m-x y l e n e ~ 0.44$ and 0.26 ; for ethylbenzene 0.37 and 0.22 ; for butylbenzene 0.47 and 0.31 ; for pinene 0.47 and 0.096 ; for terpinene 0.39 and 0.12 ; for 2-methyl-2-hexanol 0.44 and 0.26 . The uptake measurements also yielded values for the product $\mathrm{HD}_{1}^{1 / 2}$ for most of the above listed molecules studied. ( $\mathrm{H}=$ Henry's law constant, $\mathrm{D}_{1}=$ liquid phase diffusion coefficient). Uptake of the gas phase species benzene, toluene, ethanol, isoprene, was also studied and was found to be below the detection limit of the droplet apparatus. This work is being prepared for publication.

Uptake on valeric acid: The mass accommodation coefficients of gas phase butylbenzene, $\mathrm{p}$ cymene, a-pinene, and g-terpinene were measured as a function of temperature and relative humidity (R.H.) (268 K to $298 \mathrm{~K}$ ). The mass accommodation coefficients of all the listed molecules exhibit negative temperature dependence. The upper and lower values of the mass accommodation coefficients at $268 \mathrm{~K}$ and $298 \mathrm{~K}$ respectively are: for butylbenzene 0.32 and 0.15 ; for p-cymene 0.35 and 0.12 ; for -terpinene 0.43 and 0.05 ; for a-pinene 0.55 and 0.18 . The uptake measurements also yielded values for the product $\mathrm{HD}_{1}^{1 / 2}$ for a-pinene at three temperatures. $\left(\mathrm{H}=\right.$ Henry's law constant, $\mathrm{D}_{1}=$ liquid phase diffusion coefficient.) Using calculated values of $\mathrm{D}_{1}$ the Henry's law constant is obtained. The temperature dependence of $\mathrm{H}$ is expressed in the form $\ln \mathrm{H}(\mathrm{M} / \mathrm{atm})=-2.67+2960 / \mathrm{T}$. This work is being prepared for publication.

Some general principles governing the uptake of organic gases by organic liquids: The above three studies point toward some general principles governing the uptake of organic gases by organic liquids. An examination of the temperature dependence of the mass accommodation coefficient leads to the conclusion that the nucleation critical-cluster model applies also to the uptake of organic gases by organic liquids. This model was previously applied successfully to the uptake of a variety of gas phase species by aqueous surfaces 
In the nucleation critical-cluster model, the critical cluster size $\mathrm{N}^{*}$ represents the facility of a given molecule to form a critical cluster resulting in entry into the bulk liquid. This number $\mathrm{N}^{*}$ required to form a critical cluster is expected to depend on the structure of the specific molecule undergoing the uptake process. Specifically it is expected that $\mathrm{N}^{*}$ depends inversely on the attractive force between the given trace gas and the organic liquid. That is, the trace gas that has a similar structure to the organic liquid into which it is being up-taken, will have a smaller $\mathrm{N}^{*}$; in another words it will more readily form a critical cluster. Likewise, a critical cluster is more readily formed for species with a larger attractive force between the gas phase molecule and the liquid. These expectations are supported by the results of our studies. See Publications 15

9. Mass Accommodation Coefficient of Water Vapor on Aqueous Sulfuric Acid Surfaces. We report here the first experimental determination of the mass accommodation coefficient of $\mathrm{H}_{2}{ }^{17} \mathrm{O}(\mathrm{g})$ on aqueous sulfuric acid solutions. The uptake of ${ }^{17} \mathrm{O}$ labeled gas-phase water was measured as a function of temperature $250 \mathrm{~K}$ to $295 \mathrm{~K}$ and acid concentration $(50-82 \mathrm{wt} \%$ $\mathrm{H}_{2} \mathrm{SO}_{4}$ ) using a droplet train flow reactor. The mass accommodation coefficient exhibits a negative temperature dependence, consistent with the nucleation critical-cluster model of mass accommodation previously applied successfully to the uptake of a variety of gas phase species by aqueous surfaces. For $50 \mathrm{wt} \%$ sulfuric acid solution, the mass accommodation coefficient ranges from $0.50+/-0.05$ at $250 \mathrm{~K}$ to $0.41+/-0.07$ at $278 \mathrm{~K}$, and for $70 \mathrm{wt} \%$ solution it ranges from $0.69+/-0.07$ at $252 \mathrm{~K}$ to $0.54+/-0.05$ at $295 \mathrm{~K}$. The uptake coefficient of $\mathrm{D}_{2} \mathrm{O}$ was measured to be unity on $70 \mathrm{wt} \% \mathrm{H}_{2} \mathrm{SO}_{4}$, independent of temperature between $263 \mathrm{~K}$ and $293 \mathrm{~K}$. The $\mathrm{D}_{2} \mathrm{O}$ uptake coefficient is larger than the mass accommodation coefficient for $\mathrm{H}_{2}{ }^{17} \mathrm{O}$ because $\mathrm{D}-\mathrm{H}$ isotope exchange opens another channel for the disappearance of $\mathrm{D}_{2} \mathrm{O}$ from the gas phase. The $\mathrm{D}_{2} \mathrm{O}$ uptake coefficient of unity implies that the thermal accommodation coefficient of water on sulfuric acid surfaces is also unity.

We found that the mass accommodation coefficient (a) on the water-sulfuric acid solutions is well represented by:

$$
\mathbf{a}=\mathbf{a}_{\mathrm{H} 2 \mathrm{O}} \mathrm{X}(\mathrm{s})_{\mathrm{H} 2 \mathrm{O}}+\mathbf{a}_{\mathrm{H} 2 \mathrm{SO} 4}\left(1-\mathrm{X}(\mathrm{s})_{\mathrm{H} 2 \mathrm{O}}\right)
$$

where $\mathrm{X}(\mathrm{s})_{\mathrm{H} 2 \mathrm{O}}$ is the water fractional surface coverage obtained via the surface tension of the solution and the subscripted a's are the mass accommodation coefficients on pure water and pure $\mathrm{H}_{2} \mathrm{SO}_{4}$. This representation was also applied successfully to the uptake of gas phase species on ethylene glycol water solutions. The connection between this representation, and the nucleation critical-cluster model of mass accommodation was explored. See Publication 9.

\section{Morphology and Composition Studies of Soot Aerosols; Correlations Between Physical} and Chemical Properties. The importance of soot aerosols in climatology and atmospheric chemistry is now evident. The adverse health effects of soot are also well documented. Of particular importance are the climate effects of soot. Most of the work during the past year was in this area of our studies.

Soot aerosols can affect climate by direct or indirect processes. In the direct process, they alter the global radiation budget by absorbing incoming light. This reduces the net solar flux to the earth's surface. Soot particles contain both organic carbon (OC) that is relatively volatile, and a less volatile fraction commonly called black carbon (BC). The BC component 
makes soot the only strong light absorber among atmospheric aerosols. $\mathrm{BC}$ is considered to be the second most important contributor to global warming, trailing only $\mathrm{CO}_{2}$. The indirect effect is due to the ability of soot particles to serve as cloud condensation nuclei (CCN). The CCN ability of aerosols depends on their size and chemical composition. For clouds with the same liquid water path, an increase in the number of $\mathrm{CCN}$ in a cloud leads to smaller cloud droplets. These clouds are expected to be more reflective, to live longer and to produce less precipitation.

Freshly generated soot particles are initially hydrophobic and unlikely to act as CCN. However, during combustion many low vapor pressure gas products are formed. These products may then condense on existing soot aerosols. Additionally, soot particles may acquire coatings as they age, such as acids, salts, and organics. Field studies indicate that soot is found in 10 to 45 $\%$ of sulfate particles and seldom exists in pure form. Clearly, an understanding of this aging process and its effect on soot hygroscopicity is necessary to address the potential of soot to act as a CCN. The understanding of processes that transform soot from a hydrophobic aerosol to hydrophilic is one of the goals of our studies.

Soot generation by combustion is a very complex process with a large body of literature on the subject. However, the characteristics of the soot product are remarkably unaffected by the type of fuel burned. This is because all fuels tend to follow the same general combustion mechanism. The fuel first undergoes pyrolysis. By a series of radical reactions with soot precursors such as acetylene radicals, polynuclear aromatic hydrocarbons (PAHs) are formed. Further, reaction with small precursors causes the PAH structures to continue growing until they become large enough to serve as particle nuclei. The high temperature of the flame causes most of the hydrogens to be stripped away, leaving small spheres Typically $20 \mathrm{~nm}$ in diameter) composed mostly of carbon. The composition of these spheres is termed black carbon (BC). Black carbon is the nonvolatile component of soot. As the flame cools, these spheres may coagulate with each other and absorb other hydrocarbon species.

Soot characteristics are highly dependent on the flame temperature, which controls the concentration of soot precursors, the extent of dehydrogenation, and the amount and type of absorbed hydrocarbons. The temperature has been shown to affect the sooting limit and soot aerosol number density. Flame temperature may be altered by varying the fuel to air ratio. This ratio has been shown to affect macroscopic properties of soot aerosols, such as their shape and density. These properties determine the role played by soot aerosol in climate, environmental and health-related phenomena. As part of our work toward understanding the atmospheric interactions of soot, we have measured the effect of fuel to air ratio of the flame on the morphology and composition of soot aerosols. The type of important detail obtained using our aerosol mass spectrometer has previously not been available.

Experiments and results: Characterization of Soot Aerosols. Soot particles generated from combustion of propane and an $\mathrm{N}_{2} / \mathrm{O}_{2}$ mixture were size selected by a Differential Mobility Analyzer (DMA) and entrained in an atmospheric pressure laminar flow coupled to a calibrated aerosol mass spectrometer (AMS). The DMA selects particles with specific mobility diameters ranging from 75 to $400 \mathrm{~nm}$. The aerosols were characterized in terms of size, shape, density and composition. 
Studies were conducted at propane $/ \mathrm{O}_{2}$ ratios from 1.2 to 0.4 yielding two distinct types of soot aerosols, depending on the propane $/ \mathrm{O}_{2}$ ratio. We will designate the particles generated under higher propane $/ \mathrm{O}_{2}$ ratio as type 1 soot and under the lower propane $/ \mathrm{O}_{2}$ ratio as type 2 soot. The transition between these two types of soot is sharp occurring at a propane $/ \mathrm{O}_{2}$ ratio of about 0.6. At propane $/ \mathrm{O}_{2}$ ratios less than about 0.4 , soot is not observed.

Type 1 soot. At the higher propane $/ \mathrm{O}_{2}$ ratios the AMS shows a polydisperse particle size distribution with vacuum aerodynamic diameters linearly related to the DMA-determined mobility diameter; the vacuum aerodynamic diameter being about $10 \%$ larger. These aerosols have a constant density of 1.5, a dynamic shape factor of 1.2 (1 for a sphere), and a fractal dimension calculated to be 2.95 ( 3 for a sphere). These results imply that the soot particles have a compact structure. The organic molecules in this soot are mostly PAH compounds, about $70 \%$ by mass. Aliphatic hydrocarbons account for $<1 \%$ of the particle mass. By mass balance, the black carbon content of this soot was determined to be about $30 \%$.

Type 2 soot. At lower propane $/ \mathrm{O}_{2}$ ratios (i.e. a leaner flame) the soot particle morphology and composition are strikingly different. While the DMA shows a mobility diameter distribution, in the range 75 to $400 \mathrm{~nm}$ as before, the vacuum aerodynamic particle diameter is constant at about $85 \mathrm{~nm}$, independent of the mobility diameter. The particle density is also constant at 1.6. From the observed constancy of the vacuum aerodynamic diameter, the dynamic shape factor is obtained and is shown to vary from 1.5 to 3.5 over the range of mobility diameters studied. The fractal dimension of this soot is calculated to be 1.85, implying that the particle is a fractal agglomerate. The soot chemical composition is also altered. In this soot the organics are mainly aliphatic hydrocarbons $(25 \%)$, the PAH percentage is less, about $10 \%$, and the remainder is black carbon $(\sim 65 \%)$.

In a manuscript accepted for publication we discuss how the differences between these two types of soot can be understood in terms of the flame temperatures. The results of this work are compared to other types of laboratory experiments and to field studies with the overall goal of understanding the nature of soot formation.

Apparatus Upgrade. During the past five months we have upgraded the apparatus. A watercooled flat flame burner manufactured by Holthuis and Associates (flame area $\sim 12 \mathrm{~cm}^{2}$ ) was installed. The larger flame required a significantly enlarged ventilation system. This has now been completed. Both the fuel delivery and the sampling have been computerized for more accurate control.

Effect of Organic Species Condensation on Soot Particle Morphology. In a previous study, two types of soot particles were observed depending on the fuel equivalence ratio $(\phi)$ (Slowik et al. 2004). For $\phi<4.0$ (low fuel $/ \mathrm{O}_{2}$ ), the particles were irregular fractal agglomerates, composed mostly of black carbon (BC) (type 1 soot). For $\phi>4.0$ (high fuel $/ \mathrm{O}_{2}$ ), compact, near-spherical particles consisting of approximately equal amounts of $\mathrm{BC}$ and polyaromatic hydrocarbons (PAHs) were produced (type 2 soot). At the higher $\phi$ (fuel $/ \mathrm{O}_{2}$ ) the concentration of gas phase PAH compounds is greater. It was hypothesized that the differences in morphology between 
these two types of soot are due to the increased amount of condensed PAH compounds on type 2 soot particles.

In the present work we investigate this hypothesis by studying the effect of condensation and evaporation of organic species on the two types of soot. Soot particles (of one type or another) are generated in a propane flame and size-selected by a Differential Mobility Analyzer. To study the effect of condensation, the particles are passed through a region of known density and temperature of gas phase organic molecules. To study the effect of evaporation, the particles are passed through a heated interaction zone. In the final experiment to study the extent to which a deposited coating evaporates, the particles are first coated and then heated to evaporate the coating. This experiment also allows one to determine the extent to which coating brings about a re-arrangement of the spherules making up the soot particles.

The processed particles are analyzed by an Aerosol Mass Spectrometer (AMS) and a Scanning Mobility Particle Sizer (SMPS). The AMS quantitatively measures the mass spectrum of the non-refractory components of the particles and also provides the vacuum aerodynamic diameter $\left(d_{v a}\right)$, while the SMPS provides the mobility diameter $\left(d_{m}\right)$. The measured $d_{m}, d_{v a}$, and non-refractory composition are used to estimate the total particle composition, dynamic shape factor, and fractal dimension.

Our first studies are being performed with oleic acid as the condensable compound. Oleic acid serves as a surrogate for lubricating oil. Both fractal and compact particles become spherical when coated with sufficient oleic acid. The fractal particles pass through a phase intermediate between a sphere and their initial shape. This transition morphology qualitatively resembles that of diesel soot. In the experiment where the particles are heated, the fractal soot remains fractal and the compact soot remains compact. This observation indicates that the arrangement of the black carbon spherules is different in the two types of soot. When the oleic acid coating converts the fractal particles to a sphere, and then the coating is subsequently removed, the fractal character of the particles is recovered. This result together with additional planned experiments will tell us whether the oleic acid penetrates the fractal soot structure and whether it rearranges the spherules within the particle.

The observations so far suggest that the two types of soot are formed by different agglomeration processes. It seems that the PAH compounds condense on the individual spherules before the spherules agglomerate. In the compact soot the amount of PAH (probably in liquid state) is adequate to bring the spherules into a compact spherical shape. We have not yet determined whether the PAH coating then segregates to the surface, or whether it remains associated with the individual spherules. In the case of the fractal soot, the amount of condensed organics is not adequate to bring about a rearrangement of the spherules.

In the next series of experiments, compact soot particles will be coated with oleic acid and then heated to remove the coating to determine if the compact morphology is altered by the condensed organics. The three sets of experiments described above (coating, heating, and coating followed by heating) will be repeated with 1-methylnaphthalene (a PAH compound) as the condensable organic species to mimic more closely conditions in the soot forming flame. See Publications 12, 13, and 14. 


\section{PUBLICATIONS describing work sponsored by DOE award DE-FG02-98ER62581}

1 "Mass and Thermal Accommodation Coefficients of $\mathrm{H}_{2} \mathrm{O}(\mathrm{g})$ on Liquid Water as a Function of Temperature", J.L. Li, Q. Shi, P. Davidovits, D.R. Worsnop, J.T. Jayne, and C.E. Kolb. Feature article, J. Phys. Chem. A, 105, 10,627-10634, (2001).

2 "Uptake of $\mathrm{HCl}(\mathrm{g})$ and $\mathrm{HBr}(\mathrm{g})$ on Ethylene Glycol Surfaces as a Function of Relative Humidity and Temperature" Y.Q. Li, H.Z. Zhang, P. Davidovits, J.T. Jayne, C.E. Kolb, and D.R. Worsnop. J. Phys. Chem. A 106, 1220-1227, (2002)

3 "Kinetics of Submicron Oleic Acid Aerosols with Ozone: A Novel Aerosol Mass Spectrometric Technique" J.W. Morris, P. Davidovits, J.T. Jayne, J.L. Jiménez, Q. Shi, C.E. Kolb, D.R. Worsnop, W.S. Barney, G.R. Cass. Geophysical Research Letters, 29, DOI (digital object identifier) 10.1029/2002GL014692, (2002).

4 "Kinetics of Trace Gas Uptake by Liquid Surfaces" C.E. Kolb, P. Davidovits, J.T. Jayne, Q. Shi, D.R. Worsnop. Progress in Reaction Kin. and Mech.27, 1-46 (2002).

5 "Rate Constant for the Reaction of $\mathrm{Cl}_{2}(\mathrm{aq})$ with $\mathrm{OH}^{-}$" M. Gershenzon, P. Davidovits, J.T. Jayne, C.E. Kolb and D.R. Worsnop. J. Phys. Chem. A 106, 7748-7754, (2002).

6 "A Chemical Kinetics Model for Reactive Transformation of Aerosol Particles" D.R. Worsnop, J. W. Morris, Q. Shi, J.T. Jayne, and P. Davidovits and C.E. Kolb, Geophysical Research Letters, 29, DOI (digital object identifier) 10.1029/2002GL015542, (2002)

7 "Uptake of Gas Phase Species on 1-Octanol. 1. Uptake of $\alpha$-pinene, g-terpine, pcymene,and 2-methyl2- Vap hexanol, as a Function of Relative Humidity and Temperature" H.Z. Zhang, Y.Q. Li, J.R. Xia, P. Davidovits, L.R. Williams, J.T. Jayne, C.E. Kolb, D.R. Worsnop. J. Phys. Chem. 107, p 6388-6397, (2003).

8 "Uptake of Gas Phase Species on 1-Octanol. 2. Uptake of Hydrogen Halides and Acetic Acid as a Function of Relative Humidity and Temperature" H.Z. Zhang, Y.Q. Li, P. Davidovits, L.R. Williams, J.T. Jayne, C.E. Kolb, D.R. Worsnop. J. Phys. Chem. 107, p 6398-6407, (2003).

9 "Uptake of $\mathrm{H}_{2} \mathrm{O}(\mathrm{g})$ and $\mathrm{D}_{2} \mathrm{O}(\mathrm{g})$ by Aqueous Sulfuric Acid Droplets", M. Gershenzon, P. Davidovits, L.R. Williams, Q. Shi, J.T. Jayne, C.E. Kolb and D.R. Worsnop. J. Phys. Chem. A, 108, p 1567-1573, (2003).

10 "Products and Mechanisms of Ozone Reactions with Oleic Acid for Aerosol Particles Having Core-Shell Morphologies", Yasmine Katrib, Scot T. Martin, Hui-Ming Hung, Yinon Rudich, Haizheng Zhang, Jay G. Slowik, Paul Davidovits, John T. Jayne, and Douglas R. Worsnop, J. Phys. Chem. A., 108, 6686-6695, 2004. 
11 "Mass Accommodation Coefficient of Water Vapor on Liquid Water", P. Davidovits, D.R. Worsnop, J.T. Jayne, C.E. Kolb, P. Winkler, A. Vrtala, P. E. Wagner, M. Kulmala, K.E.J. Lehtinen, T. Vesala, M. Mozurkewich. Geophys. Res. Lett. 31, L2211, doi:1029/2004GL020835, (2004).

12 "Particle Morphology and Density Characterization by Combined Mobility and Aerodynamic Diameter Measurements. Part 1: Theory" P. F. DeCarlo, J.G. Slowik, D.R. Worsnop, P. Davidovits, J.L. Jimenez. Aerosol Sci. Technol. 38, 1185-1205, doi: 10.1080/027868290903907, (2004).

13 "Particle Morphology and Density Characterization by Combined Mobility and Aerodynamic Diameter Measurements." Part 2: Application to Combustion Generated Soot Aerosols as a Function of Fuel Equivalence Ratio" J.G. Slowik, K. Stainken, P. Davidovits, L.R. Williams, J.T. Jayne, C.E. Kolb, and D.R. Worsnop,Y. Rudich P. DeCarlo, J.L. Jimenez. Aerosol Sci. Technol. 38, 1206-1222, doi: 10.1080/027868290903916, (2004).

14 "Density Changes of Aerosol Particles as a Result of Chemical Reaction", Y. Katrib, S. T. Martin, Y. Rudich, P. Davidovits, J. T. Jayne, and D. R. Worsnop. Atmospheric Chemistry and Physics, 5, 275-291, (2005).

15 "Uptake of Organic Gas Phase Species on 1-Methylnaphthalen". H.Z. Zhang, P. Davidovits, L. R. Williams, J.T. Jayne, C.E. Kolb, D.R. Worsnop. J. Phys. Chem A, 109 3941-3949. (2005).

16 "Ozonolysis of Mixed Oleic-Acid/Stearic-Acid Particles: Reaction Kinetics and Chemical Morphology", Y. Katrib, G. Biskos, P. R. Buseck, P. Davidovits, J. T. Jayne, M. Mochida, M. E. Wise, D. R. Worsnop, and S. T. Martin, J. Phys. Chem. A, 109, 10910-10919, (2005). 